\title{
Minimally Invasive Surgery without Decompression for Hepatocellular Carcinoma Spinal Metastasis with Epidural Spinal Cord Compression Grade 2
}

\author{
Jong-myung Jung, ${ }^{1,2}$ Chun Kee Chung, ${ }^{2-6}$ Chi Heon $\mathrm{Kim}^{2-5}$ Seung Heon Yang ${ }^{2-5}$ \\ Department of Neurosurgery,' Spine Center, Seoul National University Bundang Hospital, Seongnam, Korea \\ Department of Neurosurgery, ${ }^{2}$ Seoul National University College of Medicine, Seoul, Korea \\ Department of Neurosurgery, ${ }^{3}$ Seoul National University Hospital, Seoul, Korea \\ Neuroscience Research Institute, ${ }^{4}$ Seoul National University Medical Research Center, Seoul, Korea \\ Clinical Research Institute, ${ }^{5}$ Seoul National University Hospital, Seoul, Korea \\ Department of Brain and Cognitive Sciences, ${ }^{6}$ Seoul National University College of Natural Sciences, Seoul, Korea
}

Objective : There is a lack of knowledge regarding whether decompression is necessary in treating patients with epidural spinal cord compression (ESCC) grade 2. The purpose of this study was to compare the outcomes of minimally invasive surgery (MIS) without decompression and conventional open surgery (palliative laminectomy) for patients with hepatocellular carcinoma (HCC) spinal metastasis of ESCC grade 2.

Methods : Patients with HCC spinal metastasis requiring surgery were retrospectively reviewed. Patients with ESCC grade 2, medically intractable mechanical back pain, a Nurick grade better than 3, 3-6 months of life expectancy, Tomita score $\geq 5$, and Spinal Instability Neoplastic Score $\geq 7$ were included. Patients with neurological deficits, other systemic illnesses and less than 1 month of life expectancy were excluded. Thirty patients were included in the study, including 17 in the open surgery group (until 2008) and 13 in the MIS group (since 2009).

Results : The MIS group had a significantly shorter operative time $(94.2 \pm 48.2$ minutes vs. $162.9 \pm 52.3$ minutes, $p=0.001)$, less blood loss (140.0 $\pm 182.9 \mathrm{~mL}$ vs. $1534.4 \pm 1484.2 \mathrm{~mL}, p=0.002)$, and less post-operative intensive care unit transfer (one patient vs. eight patients, $p=0.042$ ) than the open surgery group. The visual analogue scale for back pain at 3 months post-operation was significantly improved in the MIS group than in the open surgery group ( $3.0 \pm 1.2$ vs. $4.3 \pm 1.2, p=0.042)$. The MIS group had longer ambulation time ( $183 \pm 33$ days vs. $166 \pm 36$ days) and survival time ( $216 \pm 38$ days vs. $204 \pm 43$ days) than the open surgery group without significant difference ( $p=0.814$ and 0.959 , respectively).

Conclusion : MIS without decompression would be a good choice for patients with HCC spinal metastasis of ESCC grade 2, especially those with limited prognosis, mechanical instability and no neurologic deficit.

Key Words : Carcinoma, Hepatocellular · Spine · Neoplasm metastasis · Decompression, Surgical · Instrumentation.

- Received : October 18, 2018 •Revised : November 16, 2018 •Accepted : November 20, 2018

- Address for reprints : Chun Kee Chung

Department of Neurosurgery, Seoul National University College of Medicine, 101 Daehak-ro, Jongno-gu, Seoul 03080, Korea

Tel : +82-2-2072-2352, Fax : +82-2-744-8459, E-mail : chungc@snu.ac.kr, ORCID : https://orcid.org/0000-0003-3485-2327

This is an Open Access article distributed under the terms of the Creative Commons Attribution Non-Commercial License (http://creativecommons.org/licenses/by-nc/4.0) which permits unrestricted non-commercial use, distribution, and reproduction in any medium, provided the original work is properly cited. 


\section{INTRODUCTION}

Many cancers commonly metastasize to the spine, causing neurological symptoms, pain and a reduction in quality of life ${ }^{41)}$. Approximately 30\% of patients with cancer develop spinal metastasis, and 10\% will suffer from symptomatic metastatic spinal cord compression ${ }^{2,37,40,41)}$. The most common primary sites are the lung, breast, kidney and prostate. Hepatocellular carcinoma (HCC) is common in Asia and Africa, where the hepatitis B virus is endemic ${ }^{29)}$. In the Republic of Korea, HCC is the third most common cancer, and HCC spine metastasis is the second most common cancer of spine metastatic tumours ${ }^{29,42}$.

The goal of treatment for spinal metastasis is to improve the quality of the remaining life with preserved ambulatory function and less pain ${ }^{1)}$. The NOMS framework incorporates neurologic, oncologic, mechanical and systemic considerations to facilitate decision making in the care of patients with spinal metastases $^{28)}$. Patients with radio-resistant tumours causing high-grade epidural spinal cord compression (ESCC) were recommend to undergo surgery to provide separation between the tumour and the spinal cord (Fig. 1) ${ }^{28)}$. High-grade ESCC was defined as deformation of the spinal cord with partial (ESCC grade 2) or complete (ESCC grade 3) obliteration of the cerebrospinal fluid (CSF) space ${ }^{3)}$. However, the risks and bene ts of surgery must be weighed according to the life expectancy and the functional status of the patients ${ }^{7}$.

There is a lack of knowledge regarding whether or not palli- ative laminectomy is mandatory in the treatment of patients with ESCC grade 2. Furthermore, minimally invasive surgery (MIS) with percutaneous pedicle screw xation has become possible for spinal metastasis with the advancement of techniques and instruments ${ }^{13,39)}$. We, therefore, conducted this study to compare the outcomes of MIS without decompression and conventional open surgery (palliative laminectomy) for patients with HCC spinal metastasis of ESCC grade 2.

\section{MATERIALS AND METHODS}

From 2003 to 2015, we operated on 87 HCC spinal metastatic tumors with spinal cord compression. Among those, we selected patients with ESCC grade 2, medically intractable mechanical back pain, a Nurick grade better than 3, 3-6 months of life expectancy, Tomita score $\geq 5$, and Spinal Instability Neoplastic Score (SINS) $\geq 7$ (potentially unstable and unstable). Patients with neurological de cits, other systemic illnesses precluding surgery under general anaesthesia and less than 1 month of life expectancy were excluded. Until December 2008, our institution performed open surgeries on patients with HCC spinal metastasis with mild cord compression (ESCC grade 2). However, since January 2009, we performed MIS. These surgeries were performed by two spine surgeons. They were proficient in MIS such as endoscopic surgery as well as open surgery. Ultimately, 30 patients were included in

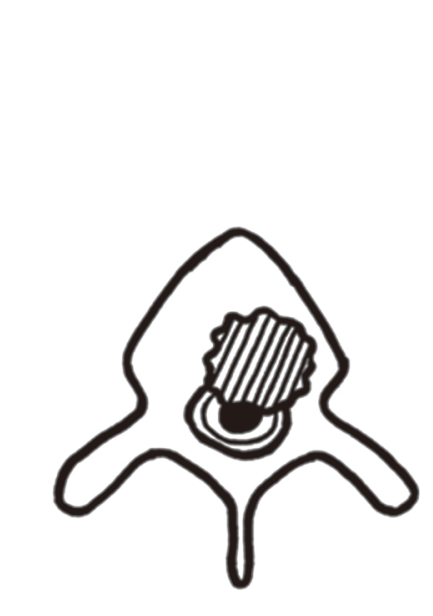

(A)

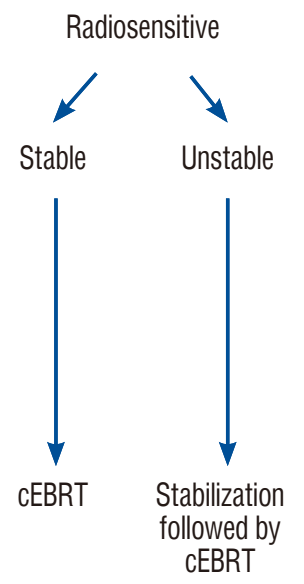

(B)

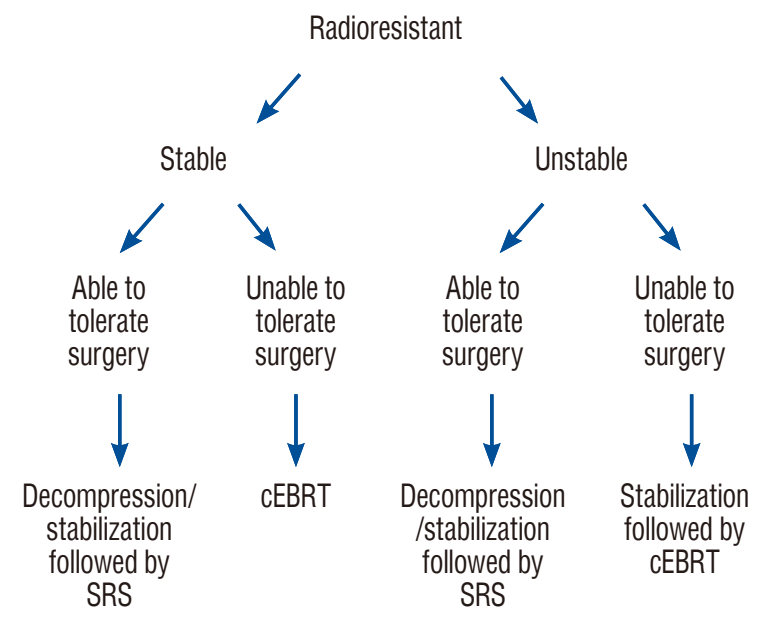

Fig. 1. Epidural spinal cord compression (ESCC) grade 2. A : Schematic representation of the ESCC grade 2. A grade of 2 indicates spinal cord compression but with cerebrospinal fluid visible around the cord. B : Current neurologic, oncologic, mechanical, and systemic decision framework of grade 2 ESCC proposed by Bilsky et al. ${ }^{3)}$. CEBRT : conventional external beam radiation therapy, SRS : stereotactic radiosurgery. 
the study, including 17 in the open surgery group and 13 in the MIS group. The present study was approved by the Institutional Review Board of Seoul National University Hospital (H-1710-092-895).

\section{Operative procedure}

In conventional open surgery, a posterior midline incision was used for pedicle screw placement. The paravertebral muscles were dissected and retracted to expose the entry points for the pedicle screws. A free hand technique was used to insert the pedicle screws. Palliative laminectomy was performed.

In MIS, the point of entry for the percutaneous pedicle screws was determined by positioning the tip of the Jamshidi needle with the tip located lateral to the pedicle oval in the true anterior-posterior fluoroscopic image and parallel to the upper endplate in the lateral fluoroscopic view. The placement of the Jamshidi needle was performed according to the modified method described by Wiesner et al. ${ }^{45}$. Thereafter, a k-wire was placed through the Jamshidi needle, and a 1.0 to $1.5 \mathrm{~cm}$ skin incision was made, followed by dissection of the deep fascia and muscles. The cannulated screw was positioned using the k-wire as a guide. The rod insertion was performed through the most cranial incision without the necessity of an extra incision.

\section{Clinical and radiologic evaluations}

The demographic and pre-operative data collected and analysed were sex, age, Child-Pugh classification (Table 1), Tomita score, SINS, Eastern Cooperative Oncology Group (ECOG) score, embolization, radiotherapy and visual analogue scale (VAS) for back pain. The operative and perioperative data collected and analysed were operative time, number of instrumented segments, total screws used, blood loss, post-operative

Table 1. Child-Pugh classification

\begin{tabular}{lccc}
\hline Parameter & 1 point & 2 points & 3 points \\
\hline Bilirubin $(\mathrm{mg} / \mathrm{dL})$ & $<2$ & $2-3$ & $>3$ \\
Serum albumin $(\mathrm{g} / \mathrm{dL})$ & $>3.5$ & $2.8-3.5$ & $<2.8$ \\
INR & $<1.7$ & $1.7-2.3$ & $>2.3$ \\
Ascites & None & Mild & Severe \\
Hepatic encephalopathy & None & Mild & Severe \\
\hline
\end{tabular}

The Child-Pugh score is calculated by adding the scores of the five factors and can range from 5 to 15. Child-Pugh class can be A (a score of 5-6), B (7-9), or C (10-15). INR : international normalized ratio intensive care unit (ICU) transfer, days of hospitalization and surgery-related complications. The post-operative data collected included post-operative VAS and ECOG at 1 month and 3 months.

\section{Assessment of ambulatory function and date of death}

The post-operative ambulatory function was assessed by review of the medical records and a telephone interview. The period before a description of loss of ambulation was regarded as the ambulatory period. If there was an event that precluded patients from independent ambulation, such as death, the period before the event was regarded as an ambulatory period. The date of an individual patient's death was retrieved from the National Health Insurance database.

\section{Statistical analysis}

All continuous variables are presented as the means \pm standard deviation. The statistical analyses were performed using Student's t-test or Mann-Whitney's U-test for continuous variables and the chi-square test or Fisher's exact test for categorical variables. A two-sided $p$-value of $<0.05$ was considered significant. Repeated-measures analysis of variance was used to compare the VAS and ECOG scores of the MIS group to those of the open surgery group at admission and at post-operative months 1 and 3. Kaplan-Meier survival analysis was used to estimate the longitudinal ambulation and survival time. All

Table 2. Baseline clinical characteristics of the two groups

\begin{tabular}{|c|c|c|c|}
\hline & $\begin{array}{c}\text { MIS } \\
(n=13)\end{array}$ & $\begin{array}{l}\text { Open surgery } \\
(n=17)\end{array}$ & $p$-value \\
\hline Sex (male : female) & $11: 2$ & $13: 4$ & 0.672 \\
\hline Age & $57.7 \pm 10.1$ & $59.6 \pm 11.1$ & 0.633 \\
\hline Child-Pugh class (A:B) & $12: 1$ & $14: 3$ & 0.613 \\
\hline Tomita score & $7.3 \pm 1.4$ & $6.4 \pm 1.3$ & 0.060 \\
\hline SINS & $9.6 \pm 0.7$ & $9.4 \pm 1.0$ & 0.438 \\
\hline Pre-operative ECOG score & $2.6 \pm 0.5$ & $2.4 \pm 0.5$ & 0.285 \\
\hline Pre-operative chemotherapy & $9(69.2)$ & $13(76.5)$ & 0.698 \\
\hline Pre-operative radiotherapy & $4(30.8)$ & $7(41.2)$ & 0.708 \\
\hline Pre-operative embolization & 0 & $5(29.4)$ & $0.032^{*}$ \\
\hline \multicolumn{4}{|c|}{$\begin{array}{l}\text { Values are presented as mean } \pm \text { standard deviation or number (\%) unless } \\
\text { otherwise indicated. Eastern Cooperative Oncology Group performance } \\
\text { status grade. *Statistical significance. MIS : minimally invasive surgery, } \\
\text { SINS : Spinal Instability Neoplastic Score, ECOG : Eastern Cooperative } \\
\text { Oncology Group }\end{array}$} \\
\hline
\end{tabular}


statistical analyses were performed using commercially available SPSS software version 21.0 (SPSS Inc., New York, NY, USA).

\section{RESULTS}

A total of 30 patients were analyzed in the present study (Table 2). Thirteen patients were in the MIS group (11 males; two females; mean age, $57.7 \pm 10.1$ years), and 17 patients were in the open surgery group (13 males; four females; mean age, $59.6 \pm 11.1$ years). The numbers of patients classified as ChildPugh class A and B were 12 and 1, respectively, in the MIS group. The numbers of patients in the open surgery group classified as A were 14 and as B were 3 . The Tomita scores were $7.3 \pm 1.4$ in the MIS group and $6.4 \pm 1.3$ in the open surgery group. SINS were 9.6 \pm 0.7 in the MIS group and $9.4 \pm 1.0$ in the open surgery group. The ECOG scores were $2.6 \pm 0.5$ in the MIS group and $2.4 \pm 0.5$ in the open surgery group. Pre-operative chemotherapy was performed in nine patients $(69.2 \%)$ in the MIS group and in 13 patients (76.5\%) in the open surgery group. Pre-operative radiotherapy was performed in four patients $(30.8 \%)$ in the MIS group and in seven patients (41.2\%) in the open surgery group. No patients underwent pre-operative embolization in the MIS group, but five patients underwent pre-operative embolization in the open surgery group ( $p=0.032$ ). There were no significant differences in the demographic and pre-operative parameters between groups, except pre-operative embolization.

For the operative and perioperative parameters, there were significant differences between the MIS group and the open surgery group in terms of operative time, blood loss and ICU stay (Table 3). The MIS group had a significantly shorter operative time than the open surgery group (94.2 \pm 48.2 minutes vs. $162.9 \pm 52.3$ minutes, respectively; $p=0.001$ ). The MIS group had significantly less blood loss than the open surgery group (140.0 $\pm 182.9 \mathrm{~mL}$ vs. $1534.4 \pm 1484.2 \mathrm{~mL}$, respectively; $p=0.002$ ). The number of patients requiring post-operative ICU transfer was significantly less in the MIS group than in the open surgery group (one patient vs. eight patients, respectively; $p=0.042$ ). There were no significant differences between the groups in level of cord compression, instrumented segments, number of screws used, number of hospital days stayed and complications. There was one perioperative complication (wound infection) in the MIS group, and there were three complications (screw pull-out, sepsis and CSF leakage) in the open surgery group. One patient in the open surgery group died on the 11th post-operative day due to sepsis.

There were no significant differences in the initial VAS for back pain between the MIS group and the open surgery group (Table 4). The VAS improved for both groups without significant differences at post-operative 1 month. However, the pain further improved in both groups at post-operative 3 months

Table 4. Visual analogue scale for back pain after the minimally invasive surgery and the open surgery

\begin{tabular}{lccc}
\hline & MIS (n=13) & $\begin{array}{c}\text { Open surgery } \\
(\mathbf{n}=\mathbf{1 7})\end{array}$ & $\boldsymbol{p}$-value \\
\hline Pre-operative & $8.7 \pm 1.4$ & $8.5 \pm 1.3$ & 0.750 \\
Post-operative 1 month & $5.5 \pm 1.3$ & $5.9 \pm 1.1$ & 0.369 \\
Post-operative 3 months & $3.0 \pm 1.2$ & $4.3 \pm 1.2$ & $0.042^{*}$ \\
\hline
\end{tabular}

Values are presented as mean \pm standard deviation. ${ }^{*}$ Statistical significance. MIS : minimally invasive surgery

Table 3. Results of surgery comparing minimally invasive surgery and open surgery

\begin{tabular}{lccc}
\hline & MIS $(\mathbf{n = 1 3 )}$ & Open surgery (n=17) & p-value \\
\hline Level of cord compression (thoracic : lumbar) & $8: 5$ & $14: 3$ & 0.242 \\
Instrumented segment & $4.6 \pm 1.4$ & $4.5 \pm 0.9$ & 0.841 \\
Number of screw & $7.2 \pm 2.6$ & $8.1 \pm 1.2$ & 0.214 \\
Operative time (minutes) & $94.2 \pm 48.2$ & $162.9 \pm 52.3$ & $0.001^{*}$ \\
Blood loss (mL) & $140.0 \pm 182.9$ & $1534.4 \pm 1484.2$ & $0.002^{*}$ \\
Post-op ICU transfer & $1(7.7)$ & $8(47.1)$ & $0.042^{*}$ \\
Hospital stay (days) & $14.8 \pm 8.5$ & $19.4 \pm 20.9$ & 0.457 \\
Complications & 1 & 3 & 0.613 \\
\hline
\end{tabular}

Values are presented as mean \pm standard deviation or number (\%) unless otherwise indicated. *Statistical significance. MIS : minimally invasive surgery, ICU : intensive care unit 
with a significant difference.

There were no statistically significant differences between the two groups when repeated measures AVONA was performed on functional status changes (Fig. 2). In the MIS group, the ECOG improved or remained unchanged in 11/13 $(84.6 \%)$ of the patients at 1 month post-operation and in 6/13 $(46.2 \%)$ of the patients at 3 months post-operation. In the open surgery group, ECOG improved or remained unchanged in $14 / 17(82.4 \%)$ of the patients at 1 month after surgery and in $7 / 17(41.2 \%)$ of the patients at 3 months after surgery.
Eleven patients $(84.6 \%)$ in the MIS group and 15 patients $(88.2 \%)$ in the open surgery group received post-operative chemotherapy. Ten patients (90.9\%) in the MIS group and 14 patients $(82.4 \%)$ in the open surgery group received post-operative radiation therapy. Among them, three patients (75\%) in the MIS group and four patients (57.1\%) in the open surgery group had already received radiotherapy before surgery.

Of the patients who had already received radiotherapy, three patients (75\%) in the MIS group and four patients (57.1\%) in the open surgery group received additional radiation therapy.
Minimally invasive surgery

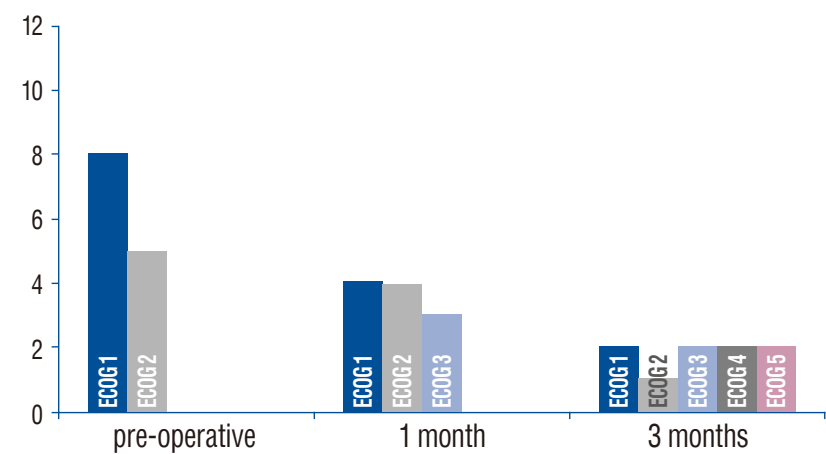

Open surgery

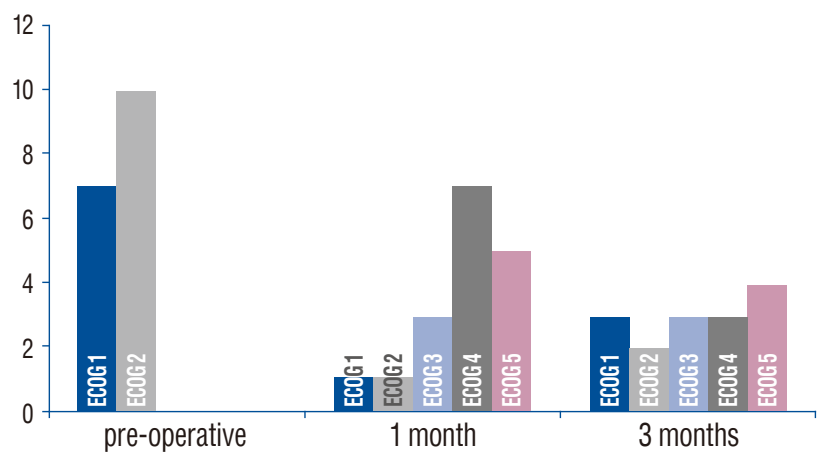

Fig. 2. Functional status (ECOG performance) changes for the minimally invasive surgery group and open surgery group pre-operatively and at postoperative 1 month and 3 months. ECOG : Eastern Cooperative Oncology Group.

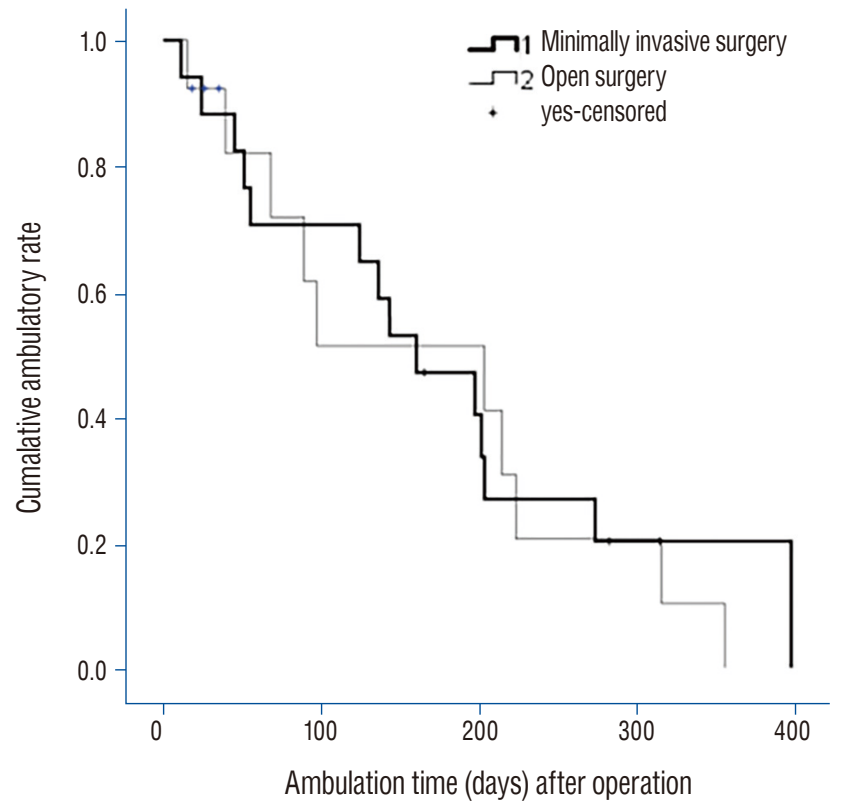

Fig. 3. The mean ambulatory time for the minimally invasive surgery group was $183 \pm 33$ days, and that for the open surgery group was $166 \pm$ 36 days $(p=0.814)$.

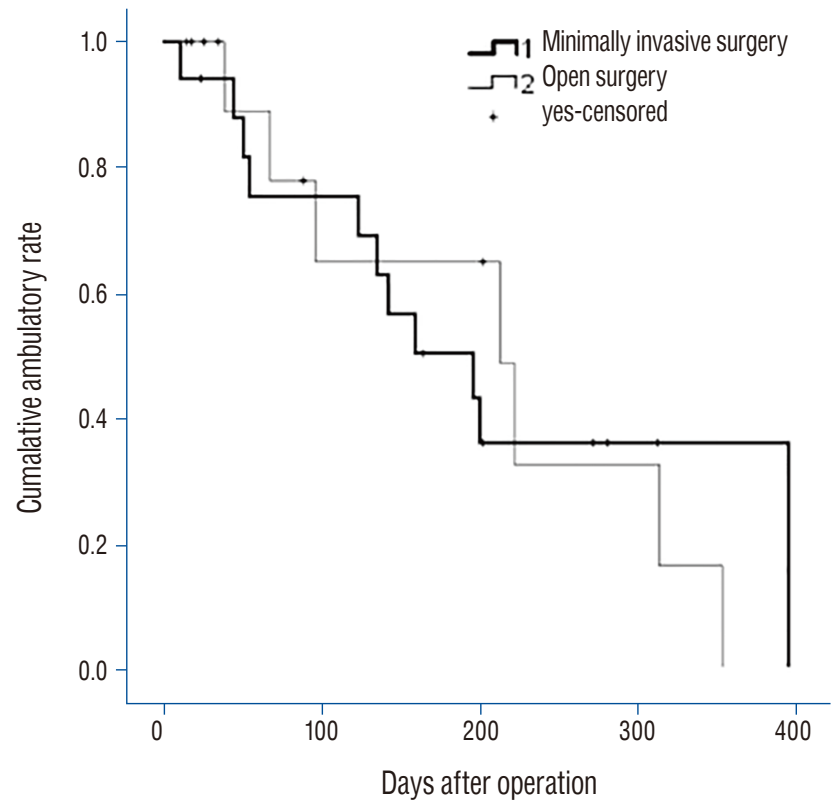

Fig. 4. The mean survival time for the minimally invasive surgery group was $216 \pm 38$ days, and that for the open surgery group was $203 \pm 43$ days $(p=0.959)$. 
The Kaplan-Meier plots of ambulation and overall survival times are shown in Figs. 3 and 4. Average ambulation time was longer in MIS group than open surgery group (183 \pm 33 days vs. $166 \pm 36$ days, respectively) and survival time was also longer in MIS group than open surgery group (216 \pm 38 days vs. $204 \pm 43$ days). However, these differences were not statistically significant ( $p=0.814$ and 0.959 , respectively).

\section{DISCUSSION}

In recent years, there has been an increase in the survival time of cancer patients due to improvements in systemic therapy for malignancies ${ }^{38)}$. Therefore, clinicians are increasingly faced with patients who present with advanced metastatic disease. Surgery with instrumentation stabilization is of great value in the management of metastatic spine disease with neurologic deficits, pain, instability, progressive deformity and fractures. Successful surgery can alleviate pain and improve quality of life $\mathrm{g}^{9,20,30,32,34,44)}$. Therefore, optimizing spinal surgery in these patients is important for preventing intraoperative and post-operative complications ${ }^{17,30)}$. However, these patients are poorer candidates for the traditional extensive open surgical approaches ${ }^{6,17,47)}$. If there has been prior radiotherapy to the surgical area, patients might have poorer wound healing. Coupled with reduced immunological status due to prior chemotherapy, these patients are highly susceptible to wound infections from the large incisions in conventional open surgery ${ }^{18,34,46)}$. Increased blood loss in conventional open spinal surgery is also associated with increased wound infection rates and mortality ${ }^{19,26,35)}$. In addition, extensive surgery might stimulate tumour growth via activation of the angiogenic pathway ${ }^{16,36)}$.

With the current technological advancements, the feasibility of MIS for patients with spinal metastasis opens up new treatment options that could be superior to conventional open surgery. The role of MIS is mechanical stabilization, and tumour control needs to be achieved by radiation therapy or chemotherapy ${ }^{10,39)}$. A multi-disciplinary approach for the treatment of spinal metastasis has been emphasized in recent studies $^{11,12,15,21,23,31)}$.

The operation time of the MIS group was significantly shorter than that of the open surgery group. A prolonged operative time is associated with an increased risk of complica- tions (infections) ${ }^{33)}$. The MIS group had significantly less blood loss than the open surgery group. MIS can lead to a safer surgery, fewer perioperative complications and faster recovery ${ }^{24,25)}$. Patients who had MIS recovered faster with a significantly shorter ICU stay than patients who had open surgery ( $0.1 \pm 0.3$ days and $0.5 \pm 0.6$ days, respectively; $p=0.022)$. This procedure will allow earlier mobilization and return to daily activities or earlier rehabilitation. Adjuvant treatments, such as chemotherapy and radiotherapy, could be initiated earlier, and the cost of hospitalization can be lessened with a shorter ICU stay. The VAS improved for both groups without a significant difference at post-operative 1 month, but the pain further improved in the MIS group, with a significant difference at post-operative 3 months $(p=0.042)$. Cancer pain can significantly affect the quality of life. Patients are likely to be bed-ridden because of intractable pain. Immobilization in bed can lead to complications, including pneumonia, pressure sores, urinary tract infections, thromboembolism and joint contractures $^{8,43)}$.

At 3 months after surgery, the ECOG deteriorated in 7/13 (53.8\%) of the patients in the MIS group and 10/17 (58.8\%) of the patients in the open surgery group. However, it is unlikely that the ECOG has deteriorated due to surgery. The median survival after diagnosis of the HCC spinal metastasis was 0.7 months for patients who received no treatment, 6 months for patients who received chemotherapy and/or radiation, and 13.5 months for patients treated with a combination of surgery and medical management ${ }^{14)}$. The prognosis of HCC depends not only on the tumor stage but also on the liver function impairment due to liver cirrhosis, which accompanies most of the patients ${ }^{4}$. LFT was significantly worse in both MIS group and open surgery group at postoperative 3 months $(p=0.012$, $p<0.001$, respectively). The ECOG deterioration was likely due to impairment of liver function.

In spinal HCC metastasis, the ambulatory status is significantly correlated with survival and ambulation time ${ }^{222}$. There were no significant differences in the ambulation time or survival time between the MIS group and the open surgery group. Considering the above findings, decompression surgery is not necessarily required for patients with HCC spinal metastasis with mild cord compression (ESCC grade 2).

Previous studies had shown neurological recovery in paralyzed patients after surgical decompression and stabilization with subsequent radiotherapy ${ }^{27,31)}$. Spinal metastasis from 
HCC has been treated with conventional radiation therapy (cRT). Another study reports that streotactic radiosurgery showed better local control compared to results achived by $\mathrm{CRT}^{5}$. In general, we recommend that the interval between radiotherapy (either stereotactic or conventional) and surgery (and vice versa) should be a minimum of 2 weeks. MIS will be able to reduce this interval. Unfortunately, the analysis of time interval was not performed because of the small number of patients.

Although we showed that MIS might be applied in select patients, there are instances in which MIS is not appropriate. In the setting of severe spinal cord compression (ESCC grade 3), MIS should not be applied, and MIS should not be considered if long-term survival is expected ${ }^{40)}$. Bone fusion should be considered for patients with expected long survival times, otherwise mechanical failure might occur. Furthermore, MIS is to be used alongside other adjuvant therapies, such as radiation or chemotherapy. If a tumour is not sensitive to either of these therapies, then one should pause before using a minimally invasive approach.

\section{Limitations of the present study}

Several limitations of our study should be mentioned. First, this study included a relatively small number of subjects, which resulted in a low statistical power. However, by examining a single histology of HCC, we avoided the confusion that arises in the majority of articles that group multiple histologies together. Second, the local control rate of adjuvant therapy after surgery (MIS and open surgery) was not investigated. MRI was not routinely performed to evaluate the effect of adjuvant treatment. However, during the follow-up period, there was no patient whose lower extremities weakness progressed without deterioration of general condition. The local control rate was considered to be acceptable. Third, the relationship between postoperative RT and VAS, ECOG, survival and ambulation could not be analyzed because many patients were treated with both postoperative RT and chemotherapy. Additional prospective study of long-term follow-up studies with substantially larger patient populations is required to more accurately clarify the effect of the postoperative RT after MIS. Fourth, this report represents a retrospective study that is inherently subject to selection bias. Prospective comparative studies comparing MIS and open surgery for HCC spinal metastasis are needed. Despite these limitations, our study con- tains valuable and clinically important information for patients in the grey zone and provides a basis for future research.

\section{CONCLUSION}

MIS without decompression could be a good alternative to conventional open surgery for patients with HCC spinal metastasis of ESCC grade 2, especially those with limited prognosis, mechanical instability and no neurologic deficit.

\section{CONFLICTS OF INTEREST}

No potential conflict of interest relevant to this article was reported.

\section{INFORMED CONSENT}

Informed consent was obtained from all individual participants included in this study.

\section{AUTHOR CONTRIBUTIONS}

\author{
Conceptualization : $\mathrm{CHK}$ \\ Data curation : SHY \\ Formal analysis : JMJ \\ Methodology : CHK \\ Project administration : CKC \\ Visualization : JMJ \\ Writing - original draft : JMJ \\ Writing - review \& editing : CKC
}

\section{- Acknowledgements}

This research was supported by the Basic Science Research Program through the National Research Foundation of Korea, funded by the Ministry of Science \& ICT (NRF2018R1A4A1025616). 


\section{References}

1. Abrahm JL, Banffy MB, Harris MB : Spinal cord compression in patients with advanced metastatic cancer: "all I care about is walking and living my life". JAMA 299 : 937-946, 2008

2. Bartels RH, van der Linden $Y M$, van der Graaf WT : Spinal extradural metastasis: review of current treatment options. CA Cancer J Clin 58 : 245-259, 2008

3. Bilsky MH, Laufer I, Fourney DR, Groff M, Schmidt MH, Varga PP, et al. : Reliability analysis of the epidural spinal cord compression scale. J Neurosurg Spine 13 : 324-328, 2010

4. Bruix J, Llovet JM : Prognostic prediction and treatment strategy in hepatocellular carcinoma. Hepatology 35 : 519-524, 2002

5. Chang UK, Kim MS, Han CJ, Lee DH : Clinical result of stereotactic radiosurgery for spinal metastasis from hepatocellular carcinoma: comparison with conventional radiation therapy. J Neurooncol 119 : 141-148, 2014

6. Cho DC, Sung JK : Palliative surgery for metastatic thoracic and lumbar tumors using posterolateral transpedicular approach with posterior instrumentation. Surg Neurol 71 : 424-433, 2009

7. Choi D, Crockard A, Bunger C, Harms J, Kawahara N, Mazel C, et al. : Review of metastatic spine tumour classification and indications for surgery: the consensus statement of the Global Spine Tumour Study Group. Eur Spine J 19 : 215-222, 2010

8. Dittmer DK, Teasell R : Complications of immobilization and bed rest. Part 1: musculoskeletal and cardiovascular complications. Can Fam Physician 39 : 1428-1432, 1435-1437, 1993

9. Falicov A, Fisher CG, Sparkes J, Boyd MC, Wing PC, Dvorak MF : Impact of surgical intervention on quality of life in patients with spinal metastases. Spine (Phila Pa 1976) 31 : 2849-2856, 2006

10. Gerszten PC, Burton SA, Ozhasoglu C, Welch WC : Radiosurgery for spinal metastases: clinical experience in 500 cases from a single institution. Spine (Phila Pa 1976) 32 : 193-199, 2007

11. Gerszten PC, Germanwala A, Burton SA, Welch WC, Ozhasoglu C, Vogel WJ : Combination kyphoplasty and spinal radiosurgery: a new treatment paradigm for pathological fractures. J Neurosurg Spine 3 : 296301, 2005

12. Gerszten PC, Monaco EA 3rd : Complete percutaneous treatment of vertebral body tumors causing spinal canal compromise using a transpedicular cavitation, cement augmentation, and radiosurgical technique. Neurosurg Focus 27 : E9, 2009

13. Gerszten PC, Welch WC : Spine: minimally invasive techniques. Prog Neurol Surg 19 : 135-151, 2006

14. Goodwin CR, Yanamadala V, Ruiz-Valls A, Abu-Bonsrah N, Shankar G, Sankey EW, et al. : A systematic review of metastatic hepatocellular carcinoma to the spine. World Neurosurg 91 : 510-517.e4, 2016

15. Halpin RJ, Bendok BR, Liu JC : Minimally invasive treatments for spinal metastases: vertebroplasty, kyphoplasty, and radiofrequency ablation. J Support Oncol 2 : 339-351; discussion 352-355, 2004

16. Hansen-Algenstaedt $N$, Algenstaedt $P$, Böttcher $A$, Joscheck C, Schwarzloh B, Schaefer $C$, et al. : Bilaterally increased VEGF-levels in muscles during experimental unilateral callus distraction. J Orthop Res 21 : 805-812, 2003

17. Hayat MJ, Howlader N, Reichman ME, Edwards BK : Cancer statistics, trends, and multiple primary cancer analyses from the Surveillance, Epidemiology, and End Results (SEER) program. Oncologist 12 : 20-37, 2007

18. Itshayek E, Yamada J, Bilsky M, Schmidt M, Shaffrey C, Gerszten P, et al. : Timing of surgery and radiotherapy in the management of metastatic spine disease: a systematic review. Int J Oncol 36 : 533-544, 2010

19. Jansson KA, Bauer HC : Survival, complications and outcome in 282 patients operated for neurological deficit due to thoracic or lumbar spinal metastases. Eur Spine J 15 : 196-202, 2006

20. Jónsson B, Sjöström L, Olerud C, Andréasson I, Bring J, Rauschning W : Outcome after limited posterior surgery for thoracic and lumbar spine metastases. Eur Spine J 5 : 36-44, 1996

21. Kim CH, Chung CK, Jahng TA, Kim HJ : Resumption of ambulatory status after surgery for nonambulatory patients with epidural spinal metastasis. Spine J 11 : 1015-1023, 2011

22. Kim CH, Chung CK, Jahng TA, Kim HJ : Surgical outcome of spinal hepatocellular carcinoma metastases. Neurosurgery $68: 888-896,2011$

23. Kim CH, Chung CK, Sohn S, Lee S, Park SB : Less invasive palliative surgery for spinal metastases. J Surg Oncol 108 : 499-503, 2013

24. Kim CW : Scientific basis of minimally invasive spine surgery: prevention of multifidus muscle injury during posterior lumbar surgery. Spine (Phila Pa 1976) 35 : S281-S286, 2010

25. Kim DY, Lee SH, Chung SK, Lee HY : Comparison of multifidus muscle atrophy and trunk extension muscle strength: percutaneous versus open pedicle screw fixation. Spine (Phila Pa 1976) 30 : 123-129, 2005

26. Kim KT, Lee SH, Suk KS, Bae SC : The quantitative analysis of tissue injury markers after mini-open lumbar fusion. Spine (Phila Pa 1976) 31 : 712-716, 2006

27. Klimo P Jr, Kestle JR, Schmidt MH : Treatment of metastatic spinal epidural disease: a review of the literature. Neurosurg Focus 15 : E1, 2003

28. Laufer I, Rubin DG, Lis E, Cox BW, Stubblefield MD, Yamada Y, et al. : The NOMS framework: approach to the treatment of spinal metastatic tumors. Oncologist 18 : 744-751, 2013

29. Park KW, Park JW, Choi J, Kim TH, Kim SH, Park HS, et al. : Survival analysis of 904 patients with hepatocellular carcinoma in a hepatitis B virus-endemic area. J Gastroenterol Hepatol 23 : 467-473, 2008

30. Pascal-Moussellard H, Broc G, Pointillart V, Siméon F, Vital JM, Sénégas $\mathrm{J}$ : Complications of vertebral metastasis surgery. Eur Spine J 7 : 438444, 1998

31. Patchell RA, Tibbs PA, Regine WF, Payne R, Saris S, Kryscio RJ, et al. : Direct decompressive surgical resection in the treatment of spinal cord compression caused by metastatic cancer: a randomised trial. Lancet $366: 643-648,2005$

32. Pointillart V, Vital JM, Salmi R, Diallo A, Quan GM : Survival prognostic factors and clinical outcomes in patients with spinal metastases. J Cancer Res Clin Oncol 137 : 849-856, 2011

33. Pull ter Gunne AF, Skolasky RL, Ross H, van Laarhoven CJ, Cohen DB : 
Influence of perioperative resuscitation status on postoperative spine surgery complications. Spine J 10 : 129-135, 2010

34. Quan GM, Vital JM, Aurouer N, Obeid I, Palussière J, Diallo A, et al. : Surgery improves pain, function and quality of life in patients with spinal metastases: a prospective study on 118 patients. Eur Spine J 20 : 1970-1978, 2011

35. Ragel BT, Kan P, Schmidt MH : Blood transfusions after thoracoscopic anterior thoracolumbar vertebrectomy. Acta Neurochir (Wien) 152 : 597-603, 2010

36. Schaefer C, Schroeder M, Fuhrhop I, Viezens L, Otten J, Fiedler W, et al. : Primary tumor dependent inhibition of tumor growth, angiogenesis, and perfusion of secondary breast cancer in bone. J Orthop Res 29 : 12511258, 2011

37. Schneider F, Greineck F, Clausen S, Mai S, Obertacke U, Reis T, et al. : Development of a novel method for intraoperative radiotherapy during kyphoplasty for spinal metastases (Kypho-IORT). Int J Radiat Oncol Biol Phys 81 : 1114-1119, 2011

38. Schroeder M, Viezens L, Wellbrock J, Fiedler W, Rüther W, Algenstaedt $P$, et al. : Sunitinib treatment reduces tumor growth and limits changes in microvascular properties after minor surgical intervention in an in vivo model of secondary breast cancer growth in bone. J Surg Oncol 113 : 515-521, 2016

39. Schwab JH, Gasbarrini A, Cappuccio M, Boriani L, De lure F, Colangeli $S$, et al. : Minimally invasive posterior stabilization improved ambulation and pain scores in patients with plasmacytomas and/or metastases of the spine. Int J Surg Oncol $2011: 239230,2011$

40. Sciubba DM, Gokaslan ZL : Diagnosis and management of metastatic spine disease. Surg Oncol 15 : 141-151, 2006

41. Sciubba DM, Petteys RJ, Dekutoski MB, Fisher CG, Fehlings MG, Ondra $\mathrm{SL}$, et al. : Diagnosis and management of metastatic spine disease. A review. J Neurosurg Spine 13 : 94-108, 2010

42. Sohn S, Kim J, Chung CK, Lee NR, Park E, Chang UK, et al. : A nationwide epidemiological study of newly diagnosed spine metastasis in the adult Korean population. Spine J 16 : 937-945, 2016

43. Teasell R, Dittmer DK : Complications of immobilization and bed rest. Part 2: other complications. Can Fam Physician 39 : 1440-1442, 1445-1446, 1993

44. Weigel B, Maghsudi M, Neumann C, Kretschmer R, Müller FJ, Nerlich M : Surgical management of symptomatic spinal metastases. Postoperative outcome and quality of life. Spine (Phila Pa 1976) 24 : 2240-2246, 1999

45. Wiesner $L$, Kothe $R$, Rüther $W$ : Anatomic evaluation of two different techniques for the percutaneous insertion of pedicle screws in the lumbar spine. Spine (Phila Pa 1976) 24 : 1599-1603, 1999

46. Wise JJ, Fischgrund JS, Herkowitz HN, Montgomery D, Kurz LT : Complication, survival rates, and risk factors of surgery for metastatic disease of the spine. Spine (Phila Pa 1976) 24 : 1943-1951, 1999

47. Zairi F, Arikat A, Allaoui M, Marinho P, Assaker R : Minimally invasive decompression and stabilization for the management of thoracolumbar spine metastasis. J Neurosurg Spine 17 : 19-23, 2012 